\title{
On the mechanism of iron oxide-induced macrophage activation: the impact of composition and the underlying signaling pathway
}

\author{
Zhengying Gu${ }^{1}$, Tianqing $\mathrm{Liu}^{2}$, Jie Tang ${ }^{1}$, Yannan Yang ${ }^{1}$, Hao Song ${ }^{1}$, Zewen K. Tuong ${ }^{3}$, Jianye Fu ${ }^{1}$, \\ Chengzhong $\mathrm{Yu}^{1,4 *}$
}

1. Australian Institute for Bioengineering and Nanotechnology, the University of Queensland, Brisbane, QLD 4072, Australia

2. QIMR Berghofer Medical Research Institute, 300 Herston Road, Brisbane, QLD, 4006, Australia

3. The University of Queensland Diamantina Institute, Translational Research Institute, Woolloongabba, QLD 4102, Australia

4. School of Chemistry and Molecular Engineering, East China Normal University, Shanghai 200241, People's Republic of China

\section{Supporting Information Placeholder}

\begin{abstract}
Iron oxide nanoparticles (IONPs) have emerging anti-cancer applications via polarizing tumor-associated macrophages from tumor-promoting phenotype (M2) to tumor-suppressing phenotype (M1). However, the underlying mechanism and structure-function relationship remain unclear. We report magnetite IONPs are more effective compared to hematite in M1 polarization and tumor suppression. Moreover, magnetite IONPs specifically rely on interferon regulatory factor 5 signaling pathway for M1 polarization and downregulate M2-assoicated arginase- 1 . This study provides new understandings and paves the way for designing advanced iron-based anti-cancer technologies.
\end{abstract}

Iron is essential for human body and has many important functions. ${ }^{1}$ Due to the significant role and compatibility of iron in biological systems, synthetic iron oxide nanoparticles (IONPs, mostly magnetite and hematite) with tailored structures and surface properties have been widely applied in diverse bio-applications. ${ }^{2} \mathrm{Re}-$ cently, IONPs have drawn specific attention in cancer immunotherapy. Carbohydrate-coated magnetite IONPs (known as Ferumoxytol) have shown promising anti-cancer potential by activating tumor-associated macrophage (TAM) from tumor-promoting phenotype (M2) to tumor-suppressing phenotype (M1). ${ }^{3} \mathrm{M} 1$ polarization was also observed in spinal cord induced by dextran-coated ferric hydroxide. ${ }^{4}$ While both iron (II, III) and iron (III) sources have been studied individually, it is unknown which form (e.g., iron (II, III) oxide or iron (III) oxide nanoparticles) is more potent in inducing M1 activation.

As a major component of immune cells infiltrating in tumors, understanding the polarization mechanism of TAMs is crucial. Among various strategies in polarizing TAMs from M2 to M1 phenotype, ${ }^{5}$ lipopolysaccharide (LPS), a bacterial component, has shown strong M1 activation performance through specific M1 signaling pathways (e.g. NF- $\kappa \mathrm{B}){ }^{6}$ The use of LPS is largely limited due to its endotoxin side effects in body. ${ }^{7}$ In addition, LPSstimulated macrophages upregulate expression of inducible nitric oxide synthase (iNOS) which exhibit controversial effects in both tumor promotion and inhibition. ${ }^{8-9}$ While IONPs could have advantage over LPS in biocompatibility, current understanding is that intracellular oxidative stress generated by iron could be correlated to $\mathrm{M} 1$ activation. $^{3}$ However, the internal signaling pathway, i.e., how IONPs switch on M1 polarization remains unclear. M1 phenotype can be activated by several transcription factors, each leading to various cytokines with unique functions in tuning local tumor environment. ${ }^{10}$ Understanding the chemistry of IONPs and their signaling pathway in macrophage activation is pivotal for ironbased anti-cancer applications.

Here, the relationship between the IONP structures and macrophage activation functions is revealed for the first time. It is shown that magnetite IONPs are more potent in M1 macrophage polarization and tumor inhibition compared to hematite IONPs (Scheme 1). The IONPs were coated by a large-pore silica layer to avoid aggregation and for future co-delivery applications. The M1 phenotype was found positively correlated to the iron-induced interferon regulatory factor 5 (IRF 5) pathway activation, without iNOS expression induced by oxidative stress-associated NF- $\kappa$ B pathway. Moreover, magnetite impaired M2 function via inhibiting arginase-1 (Arg-1) expression. Both IRF5 up-regulation and Arg-1 down-regulation favor tumor inhibition, a mechanism not found in LPS. ${ }^{11-12}$

Scheme 1. Mechanism of IONP-induced M1 Activation
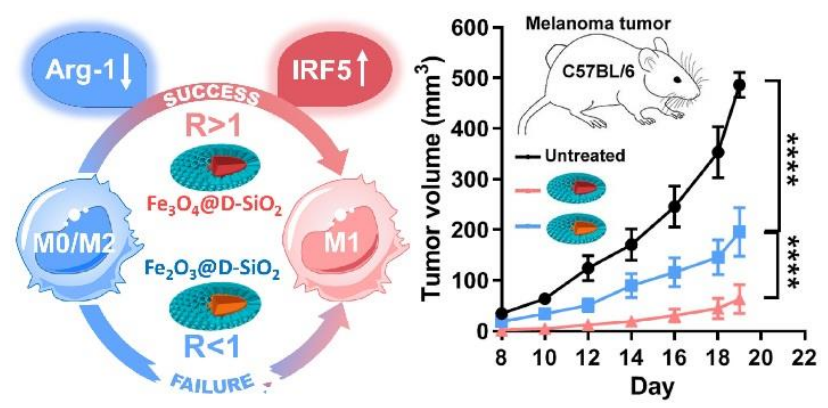

The composition of IONP significantly impacts on the ratio $(\mathrm{R})$ of intracellular iron accumulation between treated and untreated macrophages, leading to varied macrophage activation performance and anti-tumor property.

To allow for a fair comparison, magnetite and hematite IONPs with similar size, morphology and surface property were firstly designed because these parameters have significant influence on the interaction between nanoparticles and cells. ${ }^{13-14}$ Ellipsoidal hematite IONPs were prepared using a literature method with slight modifications, ${ }^{15}$ then used as the core to grow a large-pore dendritic silica 
shell (D-SiO 2 , see supporting information). ${ }^{16}$ The final product is named as $\mathrm{Fe}_{2} \mathrm{O}_{3} @ \mathrm{D}-\mathrm{SiO}_{2} . \mathrm{Fe}_{3} \mathrm{O}_{4} @ \mathrm{D}-\mathrm{SiO}_{2}$ was converted from $\mathrm{Fe}_{2} \mathrm{O}_{3} @ \mathrm{D}-\mathrm{SiO}_{2}$ in $\mathrm{H}_{2} / \mathrm{N}_{2}$ atmosphere under $450{ }^{\circ} \mathrm{C}$ for $3 \mathrm{~h}$.

Transmission electron microscopy (TEM) and scanning electron microscopy (SEM) images of $\mathrm{Fe}_{2} \mathrm{O}_{3} @ \mathrm{D}-\mathrm{SiO}_{2}$ (Fig. 1a, 1c, Fig. $\mathrm{S} 1 \mathrm{a})$ and $\mathrm{Fe}_{3} \mathrm{O}_{4} @ \mathrm{D}-\mathrm{SiO}_{2}$ (Fig. 1b, 1d, Fig. S1b) show that both nanoparticles have a core-shell structured ellipsoidal morphology with an average length of $490 \mathrm{~nm}$ and width of $320 \mathrm{~nm}$. The largepore dendritic silica shell can be clearly observed from SEM images, and further confirmed by $\mathrm{N}_{2}$ adsorption-desorption isotherms (Fig. S1 c-d). An average pore size of $\sim 40 \mathrm{~nm}$ was measured for both materials. The surface area, pore volume of two samples and their surface charge, polydispersity index (PDI) and size distribution in phosphate buffered saline (PBS) or cell culture medium are also comparable as shown in Figure S2 and summarized in Table S1.

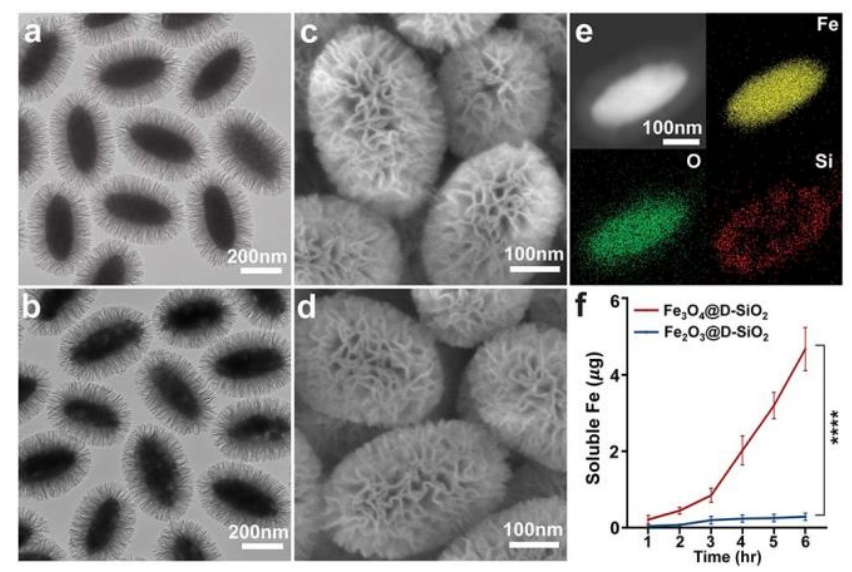

Figure 1. TEM (a, b) and SEM (c, d) images of $\mathrm{Fe}_{2} \mathrm{O}_{3} @ \mathrm{D}-\mathrm{SiO}_{2}(\mathrm{a}$, c) and $\mathrm{Fe}_{3} \mathrm{O}_{4} @ \mathrm{D}-\mathrm{SiO}_{2}(\mathrm{~b}, \mathrm{~d})$. (e) Dark-filed TEM and elemental mapping images of $\mathrm{Fe}_{3} \mathrm{O}_{4} @ \mathrm{D}-\mathrm{SiO}_{2}$. (f) $\mathrm{Fe}$ ion release profile of IONP@D-SiO 2 in PBS (pH 5).

$\mathrm{X}$-ray diffraction (XRD) measurements (Fig. S3a) indicate the successful conversion of $\mathrm{Fe}_{3} \mathrm{O}_{4}$ from $\mathrm{Fe}_{2} \mathrm{O}_{3}$. The weight percentage of iron oxide accounted for $61.97 \%$ and $62.89 \%$ in $\mathrm{Fe}_{3} \mathrm{O}_{4} @ \mathrm{D}-\mathrm{SiO}_{2}$ and $\mathrm{Fe}_{2} \mathrm{O}_{3} @ \mathrm{D}-\mathrm{SiO}_{2}$, respectively, according to $\mathrm{Fe}$ and Si measurements by inductively coupled plasma optical emission spectrometry (ICP-OES, Fig. S3b). Dark field TEM and elemental mapping ( $\mathrm{Fe}, \mathrm{O}, \mathrm{Si}$ ) images of $\mathrm{Fe}_{3} \mathrm{O}_{4} @ \mathrm{D}-\mathrm{SiO}_{2}$ (Fig. 1e) confirm the $\mathrm{Fe}_{3} \mathrm{O}_{4}$ core was confined in the silica shell. It is noted that without the silica shell (Fig. S4 a-b), magnetite IONPs cannot keep the original ellipsoidal shape of hematite and aggregated heavily due to magnetic interaction and recrystallization process. ${ }^{17-18}$ This conclusion is further supported by PDI measurements (Table S1) in PBS and the observation of sedimentation behavior of two IONPs (Fig. S4 c-d). The above results indicate that the dendritic silica shell could stabilize magnetic $\mathrm{Fe}_{3} \mathrm{O}_{4}$ in the conversion process and prevented aggregation. Consequently, magnetite and hematite IONPs with comparable structural features were obtained.

The large-pore dendritic silica coating provided not only a barrier against aggregation, but also a permeable shell to make the IONP cores available to various medium. As a quick demonstration, hollow $\mathrm{D}-\mathrm{SiO}_{2}$ nanoparticles (Fig. S5) were obtained by removing IONP core in $2 \mathrm{M} \mathrm{HCl} /$ ethanol solution.

The corresponding tomogram (Fig. S5b) sliced from the center of $\mathrm{D}-\mathrm{SiO}_{2}$ clearly revealed the porous shell and the successful removal of the IONP core. Nanoparticles with sizes less than $500 \mathrm{~nm}$ are normally internalized by cells through endocytosis and entrapped in endosome/lysosome with an acidic environment. ${ }^{19-20}$ Therefore, iron leaching kinetics of both IONPs@D-SiO 2 in acidic PBS (pH
5) was also investigated (Fig. 1f). $\mathrm{Fe}_{3} \mathrm{O}_{4} @ \mathrm{D}-\mathrm{SiO}_{2}$ showed a higher iron leaching than $\mathrm{Fe}_{2} \mathrm{O}_{3} @ \mathrm{D}-\mathrm{SiO}_{2}$ due to the weaker interaction of $\mathrm{Fe}^{2+}-\mathrm{O}$ bond present in $\mathrm{Fe}_{3} \mathrm{O}_{4}$ than $\mathrm{Fe}^{3+}-\mathrm{O}$ in $\mathrm{Fe}_{2} \mathrm{O}_{3}{ }^{21}$

The intracellular accumulation of soluble iron species was studied by incubating $\mathrm{Fe}_{3} \mathrm{O}_{4} @ \mathrm{D}-\mathrm{SiO}_{2}$ or $\mathrm{Fe}_{2} \mathrm{O}_{3} @ \mathrm{D}-\mathrm{SiO}_{2}$ with immature macrophage $(\mathrm{M} 0)$. $\mathrm{D}-\mathrm{SiO}_{2}$ was included as a negative control to understand the impact of silica. As shown in Figure 2a, $\mathrm{Fe}_{3} \mathrm{O}_{4} @ \mathrm{D}$ $\mathrm{SiO}_{2}$ treated macrophage exhibited a dramatically higher iron level in cells than $\mathrm{Fe}_{2} \mathrm{O}_{3} @ \mathrm{D}-\mathrm{SiO}_{2}$ and $\mathrm{D}-\mathrm{SiO}_{2}$ groups, mainly due to three reasons. (1) The intrinsic structure difference of IONPs leads to higher iron leaching of $\mathrm{Fe}_{3} \mathrm{O}_{4} @ \mathrm{D}-\mathrm{SiO}_{2}$ as shown in Fig. 1f. (2). $\mathrm{Fe}_{3} \mathrm{O}_{4} @ \mathrm{D}-\mathrm{SiO}_{2}$ exhibited slightly increased cellular uptake than $\mathrm{Fe}_{2} \mathrm{O}_{3} @ \mathrm{D}-\mathrm{SiO}_{2}$ (Fig. S6a), possibly contributed by magnetism-induced aggregation ${ }^{18}$ (Table S1). (3) The oxidation states of leached Fe ions from $\mathrm{Fe}_{3} \mathrm{O}_{4} @ \mathrm{D}-\mathrm{SiO}_{2}$ and $\mathrm{Fe}_{2} \mathrm{O}_{3} @ \mathrm{D}-\mathrm{SiO}_{2}\left(\mathrm{Fe}^{2+}\right.$ and $\mathrm{Fe}^{3+}$ from magnetite while only $\mathrm{Fe}^{3+}$ from hematite) may have influence on intracellular iron transport and accumulation. ${ }^{22}$ The import of $\mathrm{Fe}^{2+}$ to cytosol is more efficient than $\mathrm{Fe}^{3+}$, because extracellular or endosomal $\mathrm{Fe}^{3+}$ requires more steps to cross cell membrane compared to $\mathrm{Fe}^{2+} .{ }^{23}$ A direct comparison of $\mathrm{FeSO}_{4}$ and $\mathrm{FeCl}_{3}$ incubated with macrophages showed a higher intracellular iron accumulation of $\mathrm{FeSO}_{4}$ than that of $\mathrm{FeCl}_{3}$ (Fig. S7a), providing direct evidence of the impact of oxidation state of Fe ion on its intracellular import behavior.

It is noted that all treated groups exhibited lower intracellular iron levels compared to untreated group $(\mathrm{R}<1)$ at early stages $(<3 \mathrm{~h}$, Fig. 2a and S7a), indicating an iron exporting behavior occurred in irritated macrophages. It was reported that macrophages could lower their intracellular iron levels to protect themselves from oxidative damages, ${ }^{24}$ since all groups including $\mathrm{D}-\mathrm{SiO}_{2}$ increased reactive oxygen species (ROS) levels compared to untreated group (Fig. 2b, S7b). Because of this self-protection mechanism, the iron export overtook iron import at short incubation time $(<3 \mathrm{~h})$. At prolonged incubation time ( $>3 \mathrm{~h}$ ), only $\mathrm{Fe}_{3} \mathrm{O}_{4} @ \mathrm{D}-\mathrm{SiO}_{2}$ group exceeded untreated group in intracellular iron level $(\mathrm{R}>1)$, indicating that $\mathrm{Fe}_{3} \mathrm{O}_{4}$ IONPs are superior to $\mathrm{Fe}_{2} \mathrm{O}_{3}$ IONPs in providing a high intracellular iron level. $\mathrm{D}-\mathrm{SiO}_{2}$ showed the lowest intracellular iron level without additional iron supply.
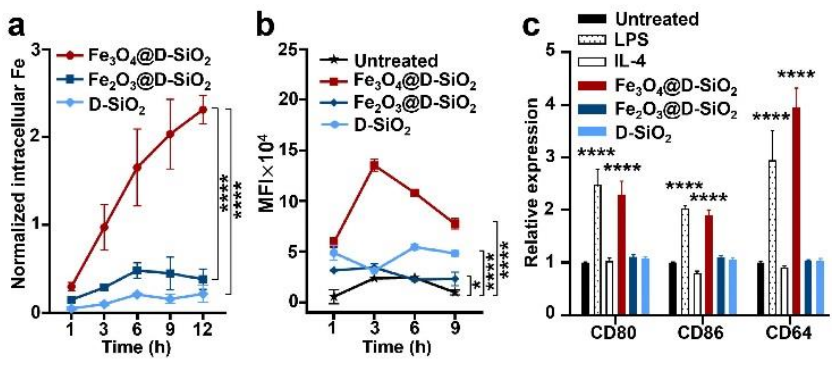

Figure 2. (a) Time-dependent intracellular iron accumulation normalized to the untreated group and (b) intracellular ROS generation. Flow cytometry analysis of CD80/CD86/CD64 (c) expression on M0 macrophage (RAW264.7) after 24 h treatment. * in (b-d) indicates the difference of treated group versus untreated group.

The M1 polarization level was investigated by the expression of three classic M1 surface markers (CD86, CD80 and CD64) ${ }^{25-26}$ after treating M 0 with the three nano-formulations, using LPS as a positive control and interleukin 4 (IL-4, potent for M2 polarization) as a negative control. As illustrated in Figure 2c, $\mathrm{Fe}_{3} \mathrm{O}_{4} @ \mathrm{D}-\mathrm{SiO}_{2}$ and LPS induced comparably high levels of CD80/CD86/CD64 expression. In contrast, $\mathrm{Fe}_{2} \mathrm{O}_{3} @ \mathrm{D}-\mathrm{SiO}_{2}$ and $\mathrm{D}-\mathrm{SiO}_{2}$ showed similar CD80/CD86/CD64 expression levels compared to untreated group.

To understand the M1 polarization mechanism, the classic M1 signaling pathways were investigated. The activation levels of four 
transcription factors (STAT1, NF- $\mathrm{B}, \mathrm{AP}-1, \mathrm{IRF} 5)^{10}$ were studied by verifying the corresponding gene expression levels. Figure $3 \mathrm{a}$ represented that $\mathrm{Fe}_{3} \mathrm{O}_{4} @ \mathrm{D}-\mathrm{SiO}_{2}$ only activated NF- $\kappa \mathrm{B}$ and IRF5, distinct from LPS where four transcription factor levels were elevated. This study was also performed in both RAW264.7 cells and bone-marrow derived macrophages (BMDM) at protein levels (see Figure S8 and discussions), further demonstrating the unique magnetite-induced transcription factor activation.

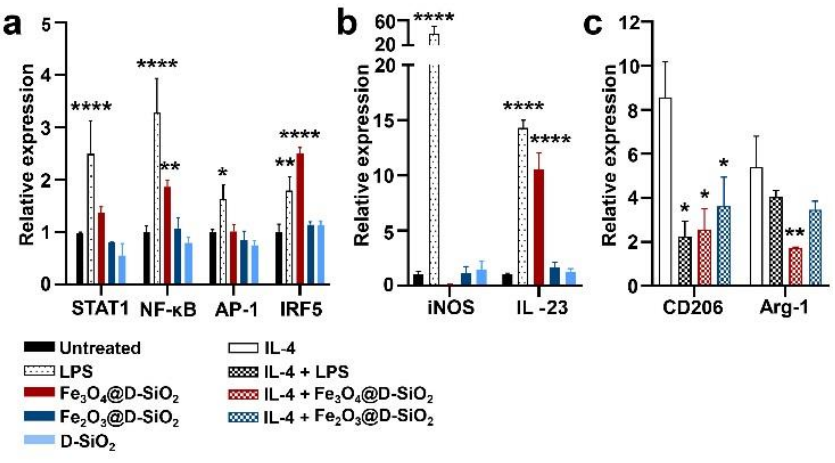

Figure 3. (a, b) Signaling pathway study of MO macrophage (RAW264.7) treated with LPS, IONP@D-SiO 2 and D-SiO 2. Gene expression levels were measured by quantitative RT-PCR (qPCR) relative to untreated control. (c) Re-activation study of M2 macrophage (RAW264.7) treated with LPS and IONP@D-SiO2. CD206/Arg-1 gene expression was determined by qPCR. M2 macrophages were obtained by IL-4 treatment $(20 \mathrm{ng} / \mathrm{mL})$. * indicates the difference of treated group versus untreated group.

The NF- $\kappa$ B activation is highly associated with intracellular ROS, ${ }^{27}$ consistent with the observation that $\mathrm{Fe}_{3} \mathrm{O}_{4} @ \mathrm{D}-\mathrm{SiO}_{2}$ induced a high intracellular ROS level. It has been demonstrated that iron involves in the ubiquitination of TNF receptor associated factor 6 (TRAF6), which is the upstream of IRF5 activation. ${ }^{28-29}$ In our experiments, the co-localization of TRAF6, ubiquitin and nanoparticles (Fig. S9) ${ }^{29}$ indicated that both $\mathrm{Fe}_{3} \mathrm{O}_{4} @ \mathrm{D}-\mathrm{SiO}_{2}$ and $\mathrm{Fe}_{2} \mathrm{O}_{3} @ \mathrm{D}-\mathrm{SiO}_{2}$ succeeded in inducing TRAF6 ubiquitination, but not $\mathrm{D}-\mathrm{SiO}_{2}$ nor LPS, suggesting the key role of iron in activation of IRF5. Compared to $\mathrm{Fe}_{3} \mathrm{O}_{4} @ \mathrm{D}-\mathrm{SiO}_{2}, \mathrm{Fe}_{2} \mathrm{O}_{3} @ \mathrm{D}-\mathrm{SiO}_{2}$ exhibited a lower level of TRAF6 ubiquitination and failed in up-regulation of IRF5 expression/M1 polarization. Our results indicate that a sufficiently high intracellular iron accumulation is important to the activation of IRF5 pathway and M1 polarization.

The downstream of NF- $\kappa \mathrm{B}$ and IRF5 was further explored by determining the gene expression level of iNOS ${ }^{10,30}$ and interleukin 23 (IL-23), ${ }^{31}$ respectively. Figures $3 b-c$ show that negligible iNOS expressed in $\mathrm{Fe}_{3} \mathrm{O}_{4} @ \mathrm{D}-\mathrm{SiO}_{2}$ group, while IL-23 exhibited high upregulation. This result demonstrated that magnetite-induced M1 macrophage only achieved phenotype from IRF5 activation but not from iNOS, possibly because iron could attenuate iNOS expression. ${ }^{32}$ Thus, even $\mathrm{Fe}_{3} \mathrm{O}_{4} @ \mathrm{D}-\mathrm{SiO}_{2}$ activated NF- $\mathrm{BB}$ via $\mathrm{ROS}$ generation, its corresponding phenotype was not expressed. Therefore, $\mathrm{Fe}_{3} \mathrm{O}_{4} @ \mathrm{D}-\mathrm{SiO}_{2}$ mediated M1 phenotype relies mainly on iron-induced IRF5-IL23 signaling pathway rather than ROS-induced NF$\kappa \mathrm{B}-\mathrm{iNOS}$ pathway. The downstream of STAT1 and AP-1 was also investigated by measuring the gene expression level of CXCL10 ${ }^{33}$ and CCL2, ${ }^{34}$ respectively. Figure S10 showed the negligible expression of CXCL10 and CCL2 induced by IONP@D-SiO 2 , consistent with the results shown in Figure 3a.

The re-activation of macrophage from M2 to M1 was also studied. CD206 and Arg-1 are surface and intracellular markers, respectively, in IL-4-induced M2 macrophage. ${ }^{25}$ Figure 3c and S11a-b depicted that magnetite-treated M2 macrophage exhibited slight up-regulation of M1 markers (CD80/CD86/CD64) and obvious down-regulation of M2 markers (CD206 and Arg-1). Importantly, only $\mathrm{Fe}_{3} \mathrm{O}_{4} @ \mathrm{D}-\mathrm{SiO}_{2}$ significantly reduced Arg-1 expression, which is associated with tumor growth and metastasis. ${ }^{12}$ The signaling activation in reprogrammed macrophage further confirmed that IRF5 was responsible for magnetite-induced M1 polarization (Fig. S11c).

To demonstrate the superior macrophage activation performance of $\mathrm{Fe}_{3} \mathrm{O}_{4} @ \mathrm{D}-\mathrm{SiO}_{2}$ against $\mathrm{Fe}_{2} \mathrm{O}_{3} @ \mathrm{D}-\mathrm{SiO}_{2}$ in vivo, their tumor inhibition performance was evaluated using a prophylactic tumor model. ${ }^{3}$ Malignant B16F10 cancer cells were implanted into right flank of female C57BL/6 mice together with IONP@D-SiO 2 . As expected, $\mathrm{Fe}_{3} \mathrm{O}_{4} @ \mathrm{D}-\mathrm{SiO}_{2}$ showed better anti-tumor performance than $\mathrm{Fe}_{2} \mathrm{O}_{3} @ \mathrm{D}-\mathrm{SiO}_{2}$ and control (Scheme 1). Figure 4 and S12 demonstrated that $\mathrm{Fe}_{3} \mathrm{O}_{4} @ \mathrm{D}-\mathrm{SiO}_{2}$ induced more $\mathrm{M} 1$ macrophages and less $\mathrm{M} 2$ macrophages in tumor site compared to $\mathrm{Fe}_{2} \mathrm{O}_{3} @ \mathrm{D}-\mathrm{SiO}_{2}$. Meanwhile, $\mathrm{Fe}_{3} \mathrm{O}_{4} @ \mathrm{D}-\mathrm{SiO}_{2}$ treatment led to longer survival rate compared to $\mathrm{Fe}_{2} \mathrm{O}_{3} @ \mathrm{D}-\mathrm{SiO}_{2}$ (Figure $\mathrm{S} 13 \mathrm{a}$ ). The tumor inhibition of IONP@D-SiO 2 was not mainly resulted from the toxicity of nanoparticles (Figure S14, Table S2 and discussions). The cytotoxic T lymphocytes (CTL) population in spleen was also higher (Figure $\mathrm{S} 13 \mathrm{~b}$ ), which is attributed to the IRF5 signaling pathway that promotes T helper 1 (Th1) response and is beneficial for CTL activation $^{35-36}$ that is widely considered crucial for anti-cancer activity. ${ }^{37}$ Basically flat weight curves of nanoparticle-treated mice indicated that no severe health problem was caused by IONP (Fig. S13c).

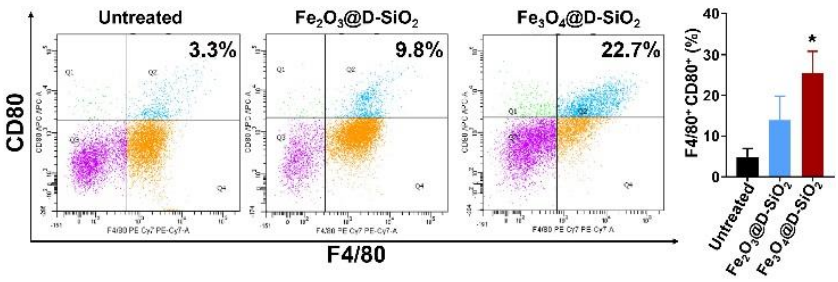

Figure 4. The population of M1 macrophages (labeled by $\mathrm{F} 4 / 80^{+}$ and $\mathrm{CD} 80^{+}$) in melanoma tumor treated with or without IONP@D$\mathrm{SiO}_{2}$ at day 12 after tumor implantation.

In summary, the chemistry of IONPs on macrophage activation and the underlying signaling pathways have been revealed. It is demonstrated that the intracellular iron level is the key for magnetite-induced M1 polarization. Instead of ROS-induced NF- $\kappa B$ pathway, iron-induced IRF5 pathway is responsible for M1 phenotype polarization, which favors CTL activation in anti-tumor activity. Understanding the unique role of iron-based nanomaterials in macrophage activation paves the way in macrophage-assisted anti-cancer therapies and future combination therapies.

\section{ASSOCIATED CONTENT}

\section{Supporting Information}

This material is available free of charge via the Internet at http://pubs.acs.org.

Experimental details on material synthesis and characterizations as well as supporting results (PDF)

\section{AUTHOR INFORMATION}

\section{Corresponding Author}

*c.yu@uq.edu.au

\section{Author Contributions}

All authors have given approval to the final version of the manuscript. 


\section{Notes}

The authors declare no competing financial interest.

\section{ACKNOWLEDGMENT}

The authors acknowledge the support from the Australian Research Council, Australian Microscopy and Microanalysis Research Facility at the Centre for Microscopy and Microanalysis and the Australian National Fabrication Facility at the University of Queensland. Z.Y.G acknowledges the Australia Research Training Program (RTP) Scholarship. Z.K.T. is supported by an Advance Queensland Research Fellowship.

\section{ABBREVIATIONS}

STAT1, Signal transducer and activator of transcription 1 ; NF- $\kappa \mathrm{B}$, nuclear factor kappa-light-chain-enhancer of activated B cells; AP1, Activator protein 1.

\section{REFERENCES}

1. Abbaspour, N.; Hurrell, R.; Kelishadi, R., Review on iron and its importance for human health. J Res Med Sci 2014, 19 (2), 164-174.

2. El-Boubbou, K., Magnetic iron oxide nanoparticles as drug carriers: preparation, conjugation and delivery. Nanomedicine 2018, 13 (8), 929952.

3. Zanganeh, S.; Hutter, G.; Spitler, R.; Lenkov, O.; Mahmoudi, M.; Shaw, A.; Pajarinen, J. S.; Nejadnik, H.; Goodman, S.; Moseley, M.; Coussens, L. M.; Daldrup-Link, H. E., Iron oxide nanoparticles inhibit tumour growth by inducing pro-inflammatory macrophage polarization in tumour tissues. Nat Nanotechnol 2016, 11 (11), 986-994.

4. Kroner, A.; Greenhalgh, Andrew D.; Zarruk, Juan G.; Passos dos Santos, R.; Gaestel, M.; David, S., TNF and increased intracellular iron alter macrophage polarization to a detrimental $\mathrm{m} 1$ phenotype in the injured spinal cord. Neuron 2014, 83 (5), 1098-1116.

5. Mantovani, A.; Marchesi, F.; Malesci, A.; Laghi, L.; Allavena, P., Tumour-associated macrophages as treatment targets in oncology. Nat Rev Clin Oncol 2017, 14, 399.

6. Lu, Y.-C.; Yeh, W.-C.; Ohashi, P. S., LPS/TLR4 signal transduction pathway. Cytokine 2008, 42 (2), 145-151.

7. Opal, S. M.; Scannon, P. J.; Vincent, J. L.; White, M.; Carroll, S. F.; Palardy, J. E.; Parejo, N. A.; Pribble, J. P.; Lemke, J. H., Relationship between plasma levels of lipopolysaccharide (LPS) and LPS-binding protein in patients with severe sepsis and septic shock. J Infect Dis 1999, $180(5), 1584-9$.

8. Vannini, F.; Kashfi, K.; Nath, N., The dual role of iNOS in cancer. Redox Biol. 2015, 6, 334-343.

9. Balkwill, F.; Joffroy, C., TNF: a tumor-suppressing factor or a tumorpromoting factor? Future Oncol. 2010, 6 (12), 1833-6.

10. Liu, Y. C.; Zou, X. B.; Chai, Y. F.; Yao, Y. M., Macrophage polarization in inflammatory diseases. Int J Biol Sci 2014, 10 (5), 520-9.

11. Fujihara, M.; Muroi, M.; Tanamoto, K.-i.; Suzuki, T.; Azuma, H.; Ikeda, H., Molecular mechanisms of macrophage activation and deactivation by lipopolysaccharide: roles of the receptor complex. Pharmacol Ther 2003, 100 (2), 171-194.

12. Mills, C. D.; Lenz, L. L.; Harris, R. A., A Breakthrough: Macrophage-Directed Cancer Immunotherapy. Cancer Res 2016, 76 (3), 513-516.

13. Niikura, K.; Matsunaga, T.; Suzuki, T.; Kobayashi, S.; Yamaguchi, H.; Orba, Y.; Kawaguchi, A.; Hasegawa, H.; Kajino, K.; Ninomiya, T.; Ijiro, K.; Sawa, H., Gold nanoparticles as a vaccine platform: influence of size and shape on immunological responses in vitro and in vivo. ACS nano 2013, 7 (5), 3926-3938.

14. Foged, C.; Brodin, B.; Frokjaer, S.; Sundblad, A., Particle size and surface charge affect particle uptake by human dendritic cells in an in vitro model. Int J Pharm 2005, 298 (2), 315-322.

15. Sugimoto, T.; Wang, Y. S.; Itoh, H.; Muramatsu, A., Systematic control of size, shape and internal structure of monodisperse alpha- $\mathrm{Fe}_{2} \mathrm{O}_{3}$ particles. Colloids Surf A 1998, 134 (3), 265-279.

16. Yang, Y. N.; Bernardi, S.; Song, H.; Zhang, J.; Yu, M. H.; Reid, J. C.; Strounina, E.; Searles, D. J.; Yu, C. Z., Anion assisted synthesis of large pore hollow dendritic mesoporous organosilica nanoparticles: understanding the composition gradient. Chem Mater 2016, 28 (3), 704 707.

17. Burke, J. E.; Turnbull, D., Recrystallization and grain growth. Prog Met Phys 1952, 3, 220-292.

18. Krajewski, M.; Brzozka, K.; Tokarczyk, M.; Kowalski, G.; Lewinska, S.; Slawska-Waniewska, A.; Lin, W. S.; Lin, H. M., Impact of thermal oxidation on chemical composition and magnetic properties of iron nanoparticles. J Magn Magn Mater 2018, 458, 346-354.

19. Kumari, S.; Swetha, M. G.; Mayor, S., Endocytosis unplugged: multiple ways to enter the cell. Cell Res 2010, 20 (3), 256-275.

20. Huotari, J.; Helenius, A., Endosome maturation. Embo J 2011, 30 (17), 3481-3500.

21. Sidhu, P. S.; Gilkes, R. J.; Cornell, R. M.; Posner, A. M.; Quirk, J. P., Dissolution of iron-oxides and oxyhydroxides in hydrochloric and perchloric acids. Clay Clay Miner 1981, 29 (4), 269-276.

22. Pantopoulos, K.; Porwal, S. K.; Tartakoe, A.; Devireddy, L., Mechanisms of mammalian iron homeostasis. Biochemistry-Us 2012, 51 (29), 5705-5724.

23. Lawen, A.; Lane, D. J. R., Mammalian iron homeostasis in health and disease: uptake, storage, transport, and molecular mechanisms of action. Antioxid Redox Sign 2013, 18 (18), 2473-2507.

24. Kong, W. N.; Duan, X. L.; Shi, Z. H.; Chang, Y. Z., Iron metabolism in the mononuclear phagocyte system. Prog Nat Sci 2008, 18 (10), 1197 1202.

25. Sun, A. R.; Friis, T.; Sekar, S.; Crawford, R.; Xiao, Y.; Prasadam, I., Is synovial macrophage activation the inflammatory link between obesity and osteoarthritis? Curr Rheumatol Rep 2016, 18 (9), 57.

26. Akinrinmade, O. A.; Chetty, S.; Daramola, A. K.; Islam, M.-U.; Thepen, T.; Barth, S., CD64: An Attractive Immunotherapeutic Target for M1-type Macrophage Mediated Chronic Inflammatory Diseases. Biomedicines 2017, 5 (3), 56.

27. Gloire, G.; Legrand-Poels, S.; Piette, J., NF-kappa B activation by reactive oxygen species: Fifteen years later. Biochem Pharmacol 2006, 72 (11), 1493-1505.

28. Takaoka, A.; Yanai, H.; Kondo, S.; Duncan, G.; Negishi, H.; Mizutani, T.; Kano, S.-i.; Honda, K.; Ohba, Y.; Mak, T. W.; Taniguchi, T., Integral role of IRF-5 in the gene induction programme activated by Tolllike receptors. Nature 2005, 434, 243.

29. Zhong, S.; Xu, J.; Li, P.; Tsukamoto, H., Caveosomal oxidative stress causes src-p21(ras) activation and lysine 63 TRAF6 protein polyubiquitination in iron-induced $\mathrm{m} 1$ hepatic macrophage activation. $J$ Biol Chem 2012, 287 (38), 32078-32084.

30. Morgan, M. J.; Liu, Z. G., Crosstalk of reactive oxygen species and NF-אB signaling. Cell Res 2011, 21 (1), 103-115.

31. Weiss, M.; Blazek, K.; Byrne, A. J.; Perocheau, D. P.; Udalova, I. A., IRF5 is a specific marker of inflammatory macrophages in vivo. Mediators Inflamm 2013, 2013, 245804.

32. Komarov, A. M.; Mattson, D. L.; Mak, I. T.; Weglicki, W. B., Iron attenuates nitric oxide level and iNOS expression in endotoxin-treated mice. Febs Lett 1998, 424 (3), 253-256.

33. Akhter, N.; Hasan, A.; Shenouda, S.; Wilson, A.; Kochumon, S.; Ali, S.; Tuomilehto, J.; Sindhu, S.; Ahmad, R., TLR4/MyD88 -mediated CCL2 production by lipopolysaccharide (endotoxin): Implications for metabolic inflammation. J Diabetes Metab Disord 2018, 17 (1), 77-84.

34. Krausgruber, T.; Blazek, K.; Smallie, T.; Alzabin, S.; Lockstone, H.; Sahgal, N.; Hussell, T.; Feldmann, M.; Udalova, I. A., IRF5 promotes inflammatory macrophage polarization and TH1-TH17 responses. Nat Immunol 2011, 12, 231.

35. van Dalen, F. J.; van Stevendaal, M. H. M. E.; Fennemann, F. L.; Verdoes, M.; Ilina, O., Molecular Repolarisation of Tumour-Associated Macrophages. Molecules 2019, 24 (1), 9-34.

36. Ekkens, M. J.; Shedlock, D. J.; Jung, E.; Troy, A.; Pearce, E. L.; Shen, H.; Pearce, E. J., Th1 and Th2 cells help CD8 T-cell responses. Infect Immun 2007, 75 (5), 2291-2296.

37. Martínez-Lostao, L.; Anel, A.; Pardo, J., How do cytotoxic lymphocytes kill cancer cells? Clin Cancer Res 2015, 21 (22), 5047-5056. 
Insert Table of Contents artwork here
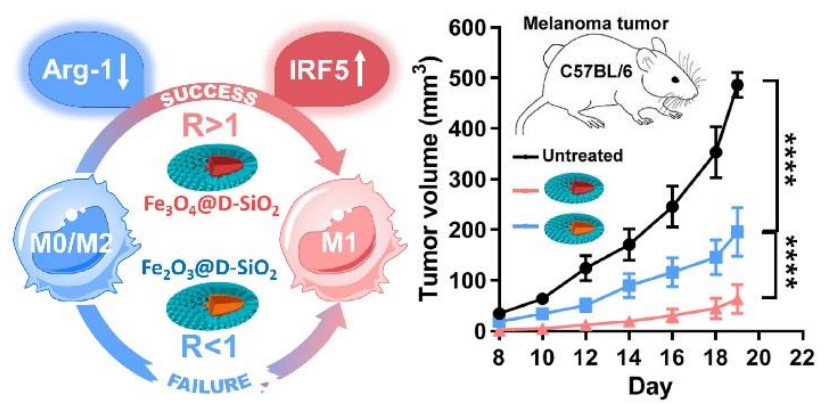